\title{
UMA REFLEXÃO SOBRE A LITERATURA INFANTIL E O DISCURSO DA DIVERSIDADE CULTURAL
}

A REFLECTION ON CHILDREN'S LITERATURE AND THE DISCOURSE ON CULTURAL DIVERSITY

\section{Sonia de Oliveira Barbosa* Luiz Cláudio Vieira de Oliveira** \\ Viviane Bernadeth Grandra} Brandão***
RESUMO:O objetivo deste artigo é refletir sobre a relação da diversidade cultural com a literatura infantil, pressupondo que essa literatura deve questionar valores e paradigmas da sociedade em que é produzida a fim de que a criança adquira uma visão crítica sobre sua cultura e sobre si mesma. Para isso, utilizamo-nos de um referencial teórico com textos já clássicos sobre literatura infantil: Carvalho (1989), Coe2007), assim como artigos de revistas acadêmicas da área. Para a fundamentação teórica sobre diversidade, diferença e alteridade, buscaram-se autores representativos, que incluem Chaú (2000), Hall (2003, 2005), Santos (2006), Silveira, Bonin e Ripoll (2010), Hunt (2010), Silva $(2000,2013)$, Foucault (1972), Bakhtin (1981) e Charaudeau (2010). Conclui-se que a diversidade cultural está permanentemente em contato com a literatura infantil, promovendo essa interação e propiciando para a crianca, a continuidade do seu processo de identidade, que é histórico, cultural, educativo e social.

PALAVRAS-CHAVE: Diversidade Cultural, Literatura Infantil, Diferença. soniab@fumec.br Mestre em Estudos Culturais Contemporâneos pela Universidade FUMEC e Professora da graduação na Universidade FUMEC.

** luizvioli@gmail.com

Doutor em Letras pela UFMG.

** viviane gandra1@hotmail.

Doutoranda em Educação pela PUC Minas, Mestre em Estudos

Culturais Contemporâneos pela Universidade FUMEC e Professor

da Universidade Estadual de Montes Claros.

ABSTRACT:The purpose of this article is to reflect on the relationship between cultural diversity and children's literature, assuming that this literature must question the values and paradigms of the society in which it is produced, so that the child can acquire a critical view about his/her culture and about him or herlsef. For this, we use a theoretical reference with already classic texts on children's literature: Carvalho (1989), Coelho (1984), Cunha (1999), Lajolo (2001), Lajolo and Zilberman $(1985,1986,2007)$ as well as articles from academic journals in the area. For the theoretical foundation on diversity, difference and otherness, we have sought representative authors, including Chauí (2000) Hall $(2003,2005)$, Santos (2006), Silveira, Bonin and Ripoll (2010), Hunt (2010), Silva $(2000,2013)$, Foucault (1972), Bakhtin (1981) and Charaudeau (2010). It is concluded that cultural diversity is permanently in contact with children's literature, promoting this interaction and providing, for the child, the continuity of their identity process, which is historical, cultural, educational and social

KEYWORDS:Cultural diversity, Children's literature, Difference. 


\section{INTRODUÇÃO}

A litera tura infantil surgiu na Europa, no século XVII, a partir da tradição literária greco-latina, mais diretamente, e de outras fontes, bem mais antigas, que remontam à Índia, ao Egito e ao Oriente. Além dessas, há as fontes célticas, em que se cultivavam os contos de fadas, há as narrativas do ciclo arturiano, os romances medievais, todos banhados no "ma ravilhoso". As várias coletâneas de contos medievais e renascentistas, como o Decameron (13481353), de Bocaccio, o Heptameron (ca. 1550), de Margarida de Navarra, e o Pentameron (1634-1636), de Giambattista Basile, constituem fontes, diretas ou indiretas, para a literatura infantil que irá se concretizar na França do séc. XVIII (COELHO, 1984, 1987).

A tradição greco-latina foi influente em toda a Europa especialmente na França. A leitura dos filósofos, dos pensadores e escritores gregos e latinos fez com que houvesse imitações, exemplos e figuras retóricas durante os debates, na Convenção, no período da Revolução Francesa, no séc. XVIII. No que se refere à literatura, em geral, um exemplo dessa influência são as fábulas: narrativas em que personagens animais são antropomorfizados, manifestando qualidades e defeitos humanos. É um recurso usado pelo fabulista para falar mais livremente do homem, ainda que de forma indireta. São narrativas curtas, normalmente acompanhadas de um fecho, que é o moral da estória. Portanto, as fábulas têm, claramente, um intuito moralizador. Pode-se citar, como exemplo, as fábulas de Esopo: "A raposa e as uvas", "O lobo e o cordeiro", "O cão e o lobo", "A rã e o boi”,“O cão e sua sombra”, entre vá rias outras, todas elas acompanhadas pela lição moral.

De Esopo a La Fontaine, a fábula se transformou através dos tempos, mantendo, entretanto, a mesma característica: docere cum delectare, isto é, instruir ao mesmo tempo em que deleitava. O prazer funciona como recurso para que a instrução se faça. Não era outra a intenção desses precursores, claramente exposta por La Fontaine. Em sua obra, há outras espécies de textos: apólogos, parábolas, alegorias, todos diferindo da fábula porque, nesta, há sempre um personagem a nimal que funciona simbolica mente: o cão é a fidelidade; a raposa é a esperteza; o leão é a força; o lobo é a injustiça; o cordeiro é a vítima inocente (COELHO, 1984). Essa função simbólica é a predominante e coocorre com outras funções que irão va riar de acordo com o leitor. Essas espécies diferem entre si, apesar de apresentar pontos de conta to (HANSEN, 1986; ECO, 1986).

Todas essas espécies textuais se ligam a outras, anteriores, que fornecem um substrato ancestral de que provieram: as parábolas, por exemplo, são bíblicas, do Antigo e do Novo Testamento; a alegoria foi bastante cultivada pelos gregos,

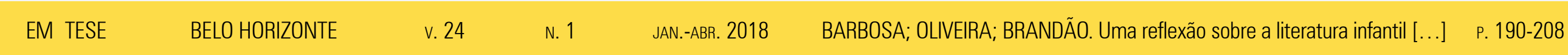

Ensino de Literatura 
que as mesclavam às narrativas míticas; os bestiários, com suas personagens-animais, têm origem medieval e são muito comuns atualmente, tanto nos quadrinhos quanto nos desenhos televisivos. Os mitos, os contos de fadas, os contos maravilhosos, os fabliaux medievais, tudo isso funciona como a base sobre a qual se construiu a literatura infantil.

A literatura infantil surge, historica mente datada, primeiramente com La Fontaine, cujo livro Fábulas foi publicado em 1668, e dedicado ao Delfim, filho de Luís XIV com a finalidade expressa de instruir. Em 1697, Perrault publica Contos da Mamãe Gansa, ta mbém voltados para as crianças. Os Irmãos Grimm, a partir de 1812, publicaram contos buscados à tradição oral e também destinados às crianças. Hans Cristhian Andersen, entre 1835 e 1842 , publicou suas obras, dirigidas ao público infantil. A partir de então, com as crianças sendo consideradas como diferentes dos adultos e carentes de uma atenção espercial, surgiu a necessidade de elas terem acesso a obra dirigidas a elas, cujo objetivo principal seria, como o fora a partir de La Fontaine, o de instruir. Além desse, houve ta mbém o desenvolvimento de novas finalidades. As obras literárias infantis tornam-se, então, um eficaz instrumento para levar os pequenos a descobrirem um mundo mágico e fantástico, sem que eles se desconectem da vida real. É também por meio das estórias que a criança tem suas curiosidade e criatividade estimuladas, aguça ndo o desejo por descobrir o novo. A leitura de livros infantis é o mecanismo pelo qual a criança participa dos mistérios e das fábulas e faz novas descobertas, de maneira prazerosa. Considerando que a leitura foi, por séculos, a única e mais importante fonte de lazer, entretenimento e aquisição de informações, é por meio dela que o ser humano se aperfeiçoa culturalmente, ao conceber e compreender o mundo em que está inserido.

Portanto, a leitura pode se valer das vivências e experiências da criança, apresentando a ela significados e sentidos que contribuem para a construção de si e do mundo, a partir de uma perspectiva de interação entre o lúdico e o real. $\mathrm{O}$ aspecto lúdico da litera tura é que vai a trair o leitor e lhe dar prazer para a fruição do texto. A variedade de textos, de autores, de pontos de vista e de estilos permitirá também, aos leitores, perceber a diversidade cultural que existe em sua volta.

Esse tema, diversidade cultural, é bastante complexo, decorrente do fato de a cultura e os aspectos que ela expressa serem construções discursivas, a partir de que se ordena o mundo, com base em apriorismos culturais, que estabelecem um jogo de semelhanças e diferenças, como elementos positivos ou negativos. Tais apriorismos são consequência das relações que se estabelecem no discurso, refletindo as relações sociais ou procurando estabelecê-las de fato. 
O objetivo deste trabalho consiste em estabelecer reflexões entre a diversidade cultural e a literatura infantil e destaca como metodologia uma revisão teórica de autores clássicos como: Zilberman e Magalhães (1982); Zilberman(2003, 2005); Carvalho (1989); Coelho (1984,1987,1991, 2000); Cunha (1999); Lajolo (2001); Lajolo e Zilberman (1985, 1986, 2007); Chauí (2000); Hall (2003 2005); Santos (2006); Bettelheim (2007); Silveira; Bonin e Ripoll (2010); Hunt (2010); Silva (2013); Foucault (1972); Bakhtin (1981) e Charaudeau (2010), de modo a ampliar a compreensão de que a diversidade cultural possibilita repensar os valores culturais, políticos e sociais relacionados à percepção do outro. Assim, rever esses princípios significa perceber a cultura como construção do indivíduo a partir das práticas sociais, bem como proporcionar o entendimento de como a "diferença" é um desafio para os valores sociais e culturais.

\section{REFLEXÃO SOBRE A DIVERSIDADE CULTURAL}

O tema da diversidade cultural é bastante complexo. Essa complexidade advém do fato de que a cultura e a diversidade que ela expressa são construções discursivas, com que se ordena o mundo, a partir de um eixo e de um ponto de vista, indicando o que é semelhante e o que é diferente. Semelhanças e diferenças, como elementos positivos ou negativos, são consequências das relações que se estabelecem no discurso. Para Charaudeau (2010) o estabelecimento dessas semelhança e diferenças depende da situação socia do sujeito comunicante e do sujeito interpretante, ou seja, do autor e do leitor do texto e preexiste ao texto.

Silveira, Bonin e Ripoll destacam a não causalidade da temática das diferenças, "que se relaciona com discursos multiculturais, pós-coloniais, pós-estruturalistas, todos com significados, objetivos e efeitos basta nte diversos". ${ }^{1}$ $\mathrm{O}$ contexto para isso foi fornecido por discussões sobre identidade e cultura, sobre direitos, sobre gênero, sobre verdades científicas desmitificadas pela própria ciência, pelo redimensionamento da comunicação humana via internet, pelas mudanças nas concepções de discurso e verdade, e pela revelação da intencionalidade e da não neutralidade discursivas.

Além desses aspectos, as autoras destacam que a diferença foi apropriada pelas redes de consumo e mercado e transformada em algo desejável: "Nesse sentido, não se trata apenas de transformar a diferença em mercadoria, mas de potencializá-la, de torná-la espetáculo, de conferir-lhe certo sentido sedutor, de convertê-la em algo novo, desejável, celebrativo." Segundo as autoras, as transformações socioculturais provocam mudanças no universo infantil e também no universo legal: os livros didáticos, os desenhos animados, as estórias em quadrinhos, os livros de ficção para crianças
1. SILVEIRA, Rosa Maria Hessel; BONIN, lara Tatiana; RIPOLL, Daniela. Ensinando sobre a diferença na literatura para crianças: paratextos, discurso cientifico e discurso multicultural, p. 99.
2. SILVEIRA, Rosa Maria Hessel; BONIN, lara Tatiana; RIPOLL, Daniela. Ensinando sobre a diferença na literatura para crianças. paratextos, discurso cientilico e discurso multiculural,

BARBOSA; OLIVEIRA; BRANDÃO. Uma reflexão sobre a literatura infantil [ [...] P. 190-208

Ensino de Literatura 
3. SILVEIRA, Rosa Maria Hessel; BONIN, lara Tatiana; RIPOLL, Daniela. Ensinando sobre a diferença na literatura para crianças: paratextos, discurso científico e discurso multicultural, p. 101. os Parâmetros Curriculares Nacionais e o sistema de cotas são exemplos dessa apropriação da diversidade.

Para Silveira, Bonin e Ripoll, que trabalharam dezenove obras de litera tura infantil, a nalisa ndo texto e paratexto que, segundo Genette (1982), é aquilo que está à volta do texto, como prefácios, orelhas, introdução -, a abordagem da diversidade se dá da seguinte forma:

Tudo ocorre, então, como se a diferença fosse uma característica própria dos sujeitos e não efeito de relações de poder e de classificações que inventamos e que produzem hierarquização, posicionando em desvantagem aqueles que consideramos diferentes a partir de normas, valores e símbolos culturais da identidade na qual nos posicionamos. Contemporaneamente, os discursos multicultura is produzem, como tendência geral, uma positivação das diferenças, tomadas como essenciais, a utorreferencia is, com valor em si mesmas. Mas tal entendimento também não problematiza as condições culturais e discursivas a partir das quais as diferenças são produzidas e reconhecidas como tal. ${ }^{3}$

Cultura e diversidade cultural são termos que, por sua própria amplitude, precisam ser definidos. Citado por Godoy e Santos (2014), Cuche (2002) escla rece que o conceito de cultura é utilizado no séc. XVIII, na França, passando depois à Alemanha e à Inglaterra. Naquele momento, cultura significava um ideal universal, sendo associada à ideia de progresso, educação e razão. Em seguida, o termo cultura se relaciona com o termo civilização, opondo-se ou ligando-se a ele. Inicialmente, civilização designava "um processo progressivo de desenvolvimento humano, um movimento em direção ao refinamento e à ordem, por oposição à barbárie e à selvageria." ${ }^{4} \mathrm{~A}$ evolução semântica dos termos mostra que, no séc. XIX, cultura irá designar as características nacionais, enqua nto civilização terá um caráter universalista.

Em seu texto, Godoy e Santos (2014) explicitam os vários conceitos de cultura, conforme as concepções antropológicas em que se inserem: a concepção descritiva de cultura, de Tylor, Boas e Malinowski; a concepção simbólica de cultura, de Leslie White e Clifford Geertz; e a concepção estrutural de cultura, de Thompson. As três concepções constituem um conjunto, complementando-se e ressaltando a necessidade desse pensar a cultura em termos particulares e independentes para cada sociedade. As formas simbólicas pelas quais a cultura se manifesta, especialmente em suas manifestações mais complexas, como a arte, "[...] pressupõem uma variedade de instituições específicas dentro e por meio das quais essas formas são produzidas, transmitidas e recebidas."

Em seguida os autores acrescenta m: "O que elas são, o modo como são formadas, circulam e são recebidas no meio
4. GODOY, Elenilton Vieira; SANTOS, Vinício de Macedo. Um olhar sobre a cultura, p. 18.

5. GODOY, Elenilton Vieira; SANTOS, Vinício de Macedo. Um olhar sobre a cultura, p. 26.

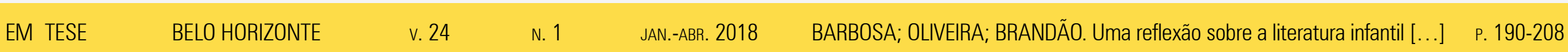


6. GODOY, Elenilton Vieira; SANTOS, Vinício de Macedo. Um olhar sobre a cultura, p. 27.

7. ALTHUSSER, Louis. Ideologia e aparelhos ideológicos do estado, $\mathrm{p}$. 43.

8. ROCHER, GUY. Culture, civilisation et idéologie, p. 4.

9. Um conjunto coeso de maneiras de pensar, de sentir, e de agir mais ou apres fidas e partihadas por uma pluralidade de pessoas, de uma maneira ao mesmo tempo objetiva e simbólica, para constituir essas pessoas em uma coletividade particular e distinta (Traducão nossa).

10. ROCHER, GUY. Culture, civilisation et idéologie, p. 5. social, bem como o sentido e o valor que têm para os que as recebem depende dos contextos e das instituições que as geram, medeiam e mantêm.” ${ }^{6}$ A cultura, portanto, depende de um conjunto de instituições, que podem ser entendidas como o que Althusser denominou de Aparelhos Ideológicos de Estado (AIE): "Designamos por Aparelhos Ideológicos de Estado um certo número de realidades que se apresentam ao observador imediato sob a forma de instituições distintas e especializadas." " Entre eles, estão os seguintes AIE: escolar, familiar, jurídico, político, sindical, da informação (imprensa, rádio, televisão), cultural (letras, Belas Artes, esportivo).

Rocher havia proposto o seguinte conceito de cultura antecipando-se aos autores supracitados:

un ensemble lié de manières de penser, de sentir et d'agir plus ou moins formalisées qui, étant apprises et partagées par une pluralité de personnes, servent, d'une manière à la fois objective et symbolique, à constituer ces personnes en une collectivité particulière et distincte. ${ }^{89}$

Rocher define cultura como: "É tudo que as pessoas têm que saber para viver em uma determinada sociedade." 10 Esse conjunto de modos de pensar partilhados tende a criar uma uniformidade, ao mesmo tempo em que possibilita certa diversidade. Vários autores já tematiza ram essa relação entre o aspecto coesivo ou mesmo coercitivo da cultura e a diversidade que ela permite: Foucault (1972), Bakhtin (1981) e Charaudeau (2010) são alguns desses autores. Foucault (1972), por exemplo, irá falar em formação discursiva, que pode ser conceituada como o conjunto de enunciados que se referem a um mesmo objeto. Segundo este a utor, se a língua dispõe de um número infinito de combinações, o discurso dispõe de um número finito, mesmo que escape a todo registro.

A formação discursiva, portanto, é caracterizada pela seguinte questão: "[...] segundo que regras um enunciado foi construído, e, consequentemente, segundo que regras outros enunciados semelhantes poderia m ser construídos?". ${ }^{11}$ Esse conjunto de regras, que permite a livre produção do discurso, ta mbém a delimita e restringe. Ao mesmo tempo, permite, delimita e restringe o pensamento. Portanto, a cultura é tudo o que as pessoas têm que pensar e saber para viver em uma sociedade e sua respectiva formação discursiva. A diferença surge a partir da ruptura, por mínima que seja, com a formação discursiva e com a ideologia que a alimenta. Entretanto, como nas sociedades há ideologias, entre as quais a ideologia de uma classe dominante, há ta mbém culturas e uma cultura dessa classe dominante. A pluralidade de classes e de culturas permitirá que haja diversidade, entre
11. FOUCAULT, Michel. As formações discursivas, p. 39.
EM TESE BELO HORIZONTE $\quad$ v. $24 \quad$ N. $1 \quad$ JAN.ABR. 2018 BARBOSA; OLIVEIRA; BRANDÃO. Uma reflexão sobre a literatura infantil [...] $\quad$ P. 190-208 
as várias culturas e ta mbém dentro de uma mesma cultura. Enquanto a cultura e a ideologia dominantes agem como forças centrípetas e conservadoras, as demais manifestações culturais e as ideologias, presentes numa sociedade, agem como forças centrífugas e inovadoras.

Por outro lado, a cultura, um dos principais conceitos abordados nas ciências humanas, pode ser definida como tudo o que é produzido pela huma nidade, desde realizações materia is a té ideias e crenças de um povo (SANTOS, 2006). Sendo assim, a cultura fixa o ser humano num meio socia ao abranger todo o cotidiano do indivíduo numa sociedade e ao permitir sua adaptação nesse meio social em que vive. por meio das relações intercultura is que os povos se comunicam e identificam as diferenças culturais. Por exemplo, a maneira de vestir, de falar, de comer, de cumprimentar, dentre outras, pressupõe que os indivíduos compreendem as regras culturais de comportamento em sua sociedade e as distinguem de outras, de diferentes sociedades. Ou que as distinguem de outras, de diversos grupos, dentro da mesma sociedade (SANTOS, 2006).

Segundo Rocher,

La culture apparaît donc comme l'univers mental, moral et symbolique, commun à une pluralité de personnes, grâce auquel et à travers lequel ces personnes peuvent communiquer entre elles, se reconnaissent des liens, des attaches, des intérêts communs, des divergences et des oppositions, se sentent enfin, chacun individuellement et tous collectivement, membres d'une même entité qui les dépasse et qu'on appelle un groupe, une association, une collectivité, une société. ${ }^{1213}$

Quando se refere às particularidades da cultura, constatam-se as variações com que cada realidade cultural apresenta sua lógica interna, sendo importante compreender o que dá sentido a suas práticas, costumes, ideias, crenças, concepções e às constantes transformações que podem ocorrer durante o tempo. O termo diversidade cultural está relacionado com as diversas ideias e concepções de mundo, com aspectos ou elementos diferentes entre si, em determinada situação ou ambiente cultural. Ou seja, relacionado com as diferentes ideologias de uma dada sociedade.

\section{Segundo Barbosa e Brandão,}

o tema da diversidade cultural propõe uma reflexão crítica acerca da cultura e de suas implicações, em especial no que se refere à relação contemporânea entre cultura, indivíduos e sociedade. Para os estudos culturais, são importantes as abordagens sobre identidade, linguagem e multiculturalismo, temas que são fundamentais para a discussão proposta sobre literatura infantil. ${ }^{14}$
12. ROCHER, GUY. Culture, civilisation et idéologi, p. 6.

13. A cultura aparece como o universo mental, moral e simbólico comum a uma pluralidade de pessoas, graças ao qual e atraves do qual estas pessoas podem se comunicar, reconhecer os laços, as referências, os interesses comuns, divergências e oposições, sentindose enfim, cada um individualmente e todos coletivamente, membros de uma entidade que os ultrapassa e que se chama um grupo, uma associação, uma coletividade, um sociedade (Tradução nossa).
EM TESE
BELO HORIZONTE
v. 24
N. 1
JAN.-ABR. 2018
BARBOSA; OLIVEIRA; BRANDÃO. Uma reflexão sobre a literatura infantil [ ...] P. 190-208

Ensino de Literatura 
15. BARROS, José Márcio (Org.). Diversidade cultural: da proteção à promoção, p. 18.

16. SILVA, Tomaz Tadeu da. Teoria cultural e educação: um vocabulário crítico, p. 44
Portanto, diversidade cultural é cultural e não natural, ou seja, resulta de trocas entre sujeitos, grupos sociais e instituições a partir de suas diferenças, desigualdades, tensões e conflitos (BARROS, 2008). ${ }^{15}$ Em relação ao conceito de diversidade cultural, Silva afirma que engloba diferentes aspectos, sendo utilizado para defender "uma política de tolerância e respeito entre as diferentes culturas". ${ }^{16}$

O relatório mundial da Unesco, intitulado Investir na diversidade cultural e no diálogo intercultural (2009), é um documento central para se discutir a pertinência do tema da diversidade cultural, uma vez que ressalta que esta é uma das questões de maior interesse no séc. XXI, quando se reconhece que a maioria dos países é constituída de sociedades multiculturais. A diversidade pode ser tomada como uma realidade positiva, que possibilita o intercâmbio entre as culturas, de forma a potencializar a riqueza que existe em cada uma delas. Por outro lado, as diferenças culturais, entre nações ou entre grupos que convivem em um mesmo espaço geográfico, podem ser a raiz de numerosos conflitos.

A Unesco (2009) aponta, como desafio da nossa época a capacidade de propormos uma perspectiva da diversidade cultural que não se configure em ameaça, mas como um benefício, uma vez que toda cultura tem contribuições efetivas a dar à comunidade internacional. O sentido do termo diversidade cultural relaciona-se à existência de uma variedade de culturas interligadas por um processo de globalização. Segundo a Unesco (2009), no entanto, a diversidade cultural nem sempre resulta no convívio harmônico das culturas: "Perante essa variedade de códigos e perspectivas, os estados nem sempre encontram as respostas apropriadas, por vezes urgentes, nem logram colocar a diversidade cultural ao serviço do bem comum." ${ }^{17}$

Ainda de acordo com a Unesco (2009), os vetores língua, educação, comunicação, conteúdos cultura is, bem como cria tividade e mercados, são domínios que trazem possibilidades de entendimento intercultural e proporcionam repensar as complexas questões sociocultura is que existem no mundo atual. A Unesco (2009) apresenta a questão da diversidade linguística no âmbito da diversidade cultural, como espelhamento de adaptação criativa dos povos às alterações no meio social, bem como no seu ambiente físico. "Nesse sentido, as línguas não são somente um meio de comunicação, mas representam a própria estrutura das expressões culturais e são portadoras de identidade, valores e concepções de mundo" 18

Desde sempre, a língua foi o meca nismo de comunicação da huma nidade, permitindo aos humanos relacionarem-se uns com outros, expondo seus conhecimentos e pensamentos verbalmente, pela escrita e por outras formas de linguagem. Pela linguagem, foi possível estabelecer uma relação
17. UNESCO. Relatório Mundial da UNESCO. investir na diversidade

18. UNESCO. Relatório Mundial da UNESCO: investir na diversidade cultural e no diálogo intercultural, p. 14

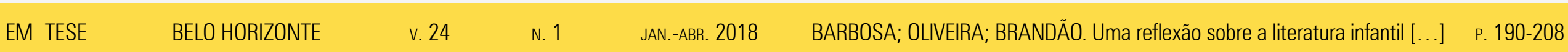


social, fazendo interagir culturas e ideologias e resultando num processo de difusão de conhecimentos. É pela linguagem, principalmente, que se veicula a visão de mundo de uma sociedade e de suas culturas.

Chauí (2000) apresenta a definição da linguagem como via de acesso ao pensamento e mundo, e revela que afirmar que os seres são falantes é o mesmo que dizer que são linguagem. Esta é uma criação da humanidade, de uma instituição sociocultural, ao mesmo tempo em que cria os indivíduos, como seres sociais e culturais.

A linguagem é nossa via de acesso ao mundo e ao pensamento, ela nos envolve e nos habita, assim como a envolvemos e a habitamos. Ter experiência da linguagem é ter uma experiência espantosa: emitimos e ouvimos sons, escrevemos e lemos letras, mas, sem que saibamos como, experimentamos e compreendemos sentidos, significados, significações, emoções, desejos, ideias. [...] É que a linguagem tem a capacidade especial de nos fazer pensar enquanto falamos e ouvimos, de nos levar a compreender nossos próprios pensamentos tanto quanto os dos outros que falam conosco. As palavras nos fazem pensar e nos dão o que pensar porque se referem a significados, tanto os já conhecidos por outros quanto os já conhecidos por nós, bem como os que não conhecíamos e que descobrimos por estarmos conversando.
Coelho e Mesquita (2013) concordam com Chauí na conceituação acima transcrita. Compreendem que a linguagem se ca racteriza como o alicerce da vida social e está presente em diversos a mbientes: "social, político, religioso, fa miliar, educacional, ideológico, midiático, econômico, a moroso. Por fim, a linguagem é o que medeia as relações socia is, permitindo que nos inscreva mos neste ou naquele lugar social." ${ }^{19}$ Hall (2003) apresenta a linguagem a partir da concepção de que não existe um significado fixo na mensagem entre emissor e receptor, e a define como:

A linguagem, em seu sentido mais amplo, é o veículo do raciocínio prático, do cálculo e da consciência, por causa das formas pelas quais certos significados e referências têm sido historicamente confirmados. Mas seu poder de convencimento depende da "lógica" que conecta uma proposição a outra na cadeia de significados; onde as conotações sociais e o significado histórico estão condensados e reverberam um no outro. ${ }^{20}$

Observa-se que Hall (2003), com sua afirmativa sobre a linguagem, refere-se à a usência de um significado fixo no processo de comunicação. A linguagem é um instrumento persuasivo que só se impõe por meio das interações sociais, em que os signos passam a ter significação a partir dos interesses das relações sociais. Para Barbos, "essa flutuação
19. COELHO, L. P.; MESOUITA, D. P. C. Lingua, cultura e identidade: conceitos intrínsecos e interdependentes, p. 26.

20. HALL, Stuart. Da diáspora. identidades e mediações culturais, p. 286.

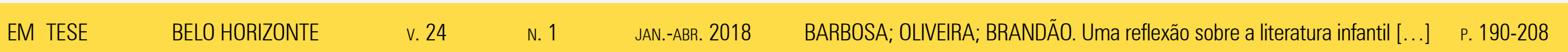


21. BARBOSA, Sonia de Oliveira. $A$ literatura infantil brasileira $e$ diversidade cultural, p. 37.

22. CANDIDO, Antonio. In: FESTER, A. C. Ribeiro (Org.). Direitos Humanos e Literatura, p. 112 do sentido, possibilitando novas significações, permite à litera tura infantil ter diferentes leituras, além de apresentar e discutir a diversidade". ${ }^{21}$

\section{RELAÇÃO DA DIVERSIDADE CULTURAL}

\section{E A LITERATURA INFANTIL}

Antonio Candido, em seu texto Direitos Humanos e Literatura (1989), conceitua literatura de uma forma bastante ampla. Dentro desse conceito, inclui-se o que se classifica como literatura infantil, que chega a constituir um gênero.

Chamarei de literatura, de maneira mais ampla possível, todas as criações de toque poético, ficcional ou dramático em todos os níveis de uma sociedade; em todos os tipos de cultura, desde o que chamamos de folclore, lenda, chiste, e até as formas mais complexas e difíceis da produção escrita das grandes civilizações. ${ }^{22}$

Marisa Lajolo, em seu texto de 2001, destaca uma série de características do texto literário que podem ser expressas pelo termo litera riedade, ou seja, aquilo que faz com que um texto seja assumido como literário:

[...] 1) a oposição da linguagem literária à linguagem comum, sendo a literatura uma forma textual que coloca em primeiro plano a própria linguagem, ou seja, há ênfase na função poética dessa linguagem; 2) a integração da linguagem como organização especial de palavras e estruturas que estabelecem relações específicas entre si, potencializando o sentido dos textos; 3) a distinção entre o caráter referencial dos textos não literários e o caráter ficcional dos textos literários; 4) os textos literários teriam um fim em si mesmos, pois, ao colocar a própria linguagem em primeiro plano, estariam operando o seu caráter estético, que ocasionaria, por sua vez, o prazer nos receptores desse texto. ${ }^{23}$

A valoração da literatura infantil por meio da literariedade, reduz a importância de outros, extratextuais, como o de criança e de infância. Peter Hunt (2010), citado por Barbosa (2016, p. 40), destaca a multiplicidade de definições de infância, em relação a livros dedicados à criança.

Em suma, a infância não é hoje (se alguma vez foi) um conceito estável. Por conseguinte, não se pode esperar que a literatura definida por ela seja estável [...], pois os conceitos de infância vão alterar radicalmente o texto e são muito mais instáveis que os conceitos referentes aos adultos [...] a cultura do livro toma decisões sobre a infância, e em diversos sentidos a cria ou a destrói. ${ }^{24}$

De acordo com Barbosa, o conceito de literariedade, ao incluir a literatura infantil no conjunto maior do que
33. LAJOLO, M. Literatura: leitores leitura, p. 39

24. HUNT Peter Crítica, teoria literatura infantil, p. 94-95.

\begin{abstract}
EM TESE BELO HORIZONTE $\quad$ V. $24 \quad$ N. $1 \quad$ JAN.-ABr. 2018 BARBOSA; OLIVEIRA; BRANDÃO. Uma reflexão sobre a literatura infantil [...] P. 190-208
\end{abstract}


25. BARBOSA, Sonia de Oliveira. $A$ diteratura infantil brasileira e a

26. CARVALHO, Bárbara Vasconcelos de. A literatura infantil: visão histórica e crítica, p. 194 se denomina literatura, dá-lhe uma especificidade única. Quando se usa o sintagma "literatura infantil" para caracterizar um tipo de literatura deve-se destacar que sua valoração se dará por sua literariedade, tal como definida anteriormente:

Ao preencher esses requisitos da literariedade, a literatura infantil é, realmente, um tipo de literatura que apresenta qualidades compatíveis com aquelas pertencentes à literatura, em geral. A literatura infantil é objeto de estudos críticos, a partir do séc. XVIII, que consideram, ao mesmo tempo, os conceitos de criança e, ou, de infância, presentes no determinante que especifica o tipo de literatura, no sintagma "literatura infantil", distinguindo-a da literatura adulta. Esse determinante (infantil) deixa claro que houve uma intencionalidade na produção de textos para um leitor específico, a criança. Ainda que, à época do surgimento da literatura in fantil, o conceito de infância não fosse muito claro, ele é importante para se delimitar o que seja a literatura infantil. ${ }^{25}$

Nem sempre a literatura infantil é valorada por sua literariedade. Muitas vezes, essa litera tura é utilizada como um "veículo educativo e considerando-se a permeabilidade da criança diante dos estímulos e motivações, é considerável o efeito que possa causar no comportamento do leitor em fase de formação". ${ }^{26}$ Em vez de se buscar a fruição do texto literário, tenta-se transformá-lo numa forma de incutir na criança valores e crenças da sociedade a que pertence. Aproveita-se da docilidade da criança, "em fase de formação", para provocar efeitos em seu comportamento, isto é, em sua forma de estar no mundo dos adultos. Assim, como diz a autora, a literatura infantil é apenas um "veículo", não um valor um si.

A postura de Zilberman (2003) é bastante diversa da posição de Carvalho (1989), uma vez que defende a criação de um leitor por meio do domínio da palavra escrita. Ao ler, a criança é introduzida num universo de signos, mais diversificado e complexo, que ela passa a compreender, semioticamente, acrescentando novos códigos ao código da leitura. Portanto, para Zilberman, a literatura infantil não é um instrumento para se alcançar a submissão da criança, mas a sua libertação. Nesse sentido, educação adquire um sentido a mplo: o leitor se torna sujeito e capaz de produzir suas próprias versões sobre o conteúdo que lhe é apresentado. Deixa de ser passivo, reprodutor de conteúdos, e passa a ser ativo.

O contato com a literatura infantil se faz inicialmente através de seu ângulo sonoro: a criança ouve histórias narradas por adultos, podendo eventualmente acompanhá-las com os olhos na ilustração. É essa última que introduz a epiderme gráfica do livro, de modo que a palavra escrita apresenta-se

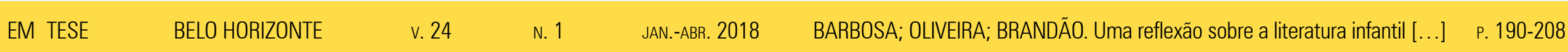


27. ZILBERMAN, Regina. $A$ literatura infantil na escola, p. 57. via de regra como o derradeiro elo de uma cadeia que une o indivíduo à obra literária. Contudo, tão logo ela se instala no domínio cognitivo de um ser humano, converte-o num leitor, isto é, modifica a sua condição. Portanto, é a posse dos códigos de leitura que muda o status da criança e integra-a num universo maior de signos, o que nem a simples audição, nem o deciframento das imagens visuais permitiam. ${ }^{27}$

A leitura é um processo de apropriação e transformação da informação. Como o emprego do código linguístico se faz por meio de mudanças, altera ndo ou criando palavras e significações, a leitura propicia que o leitor seja também um criador de novos sentidos. Nesse sentido, Yunes e Pondé afirmam que a leitura ajuda a criança a reelaborar o real, de forma lúdica:

Para a criança, o processo psíquico de identificação (a interação de subjetividade que nos lança para dentro dos livros) é ainda mais forte; daí a necessidade de o escritor ter consciência plena do seu mister. Os papéis propostos pelos personagens são vividos pela imaginação infantil com a força de um drama real. Por esta via, texto e leitor se fundem - o que acentua a possibilidade de impressão, sobre a consciência do leitor, dos modelos de comportamento e dos conflitos vividos (ideologia) no universo. A leitura, para a criança, bem mais que um meio de evasão ou de socialização, é um meio de representação do real. Desse modo, o texto ajuda-a a reelaborar o real, sob a forma do jogo e da ficção. ${ }^{28}$

O livro deve colaborar para que a criança realize essa reelaboração do real. Quanto mais o livro desenvolver a sua própria literariedade, maiores serão as chances de as crianças reelabora rem o real. Por outro lado, quando ma is o livro procurar "desenvolver comportamentos", maiores serão as possibilidades de se usar a literatura infantil para inculcar determinados valores e crenças nas crianças. Portanto, pode haver um uso ideológico ou contraideológico, dependendo do momento histórico da cultura em que a literatura infantil é produzida. Assim, haverá uma valorização da diversidade, por meio da consideração do outro, ou haverá uma desvalorização, com a crítica a toda e qualquer diferença.

A literatura infantil, destinada a provocar "determinados comportamentos", terá um uso cla ramente ideológico, reiterando o mesmo e negando a diversidade. O que se pretende, neste texto, é questionar esse emprego ideológico e indicar que, quando se valoriza a diversidade questionam-se os paradigmas socioculturais vigentes numa determinada sociedade, assim como se colocam em discussão as ideias de centro e periferia, de mesmo e de outro, de certo e de errado, de normal e de não normal. Segundo Barbosa, há
28. YUNES, Eliana; PONDÉ, Glória. Leitura e leituras da literatura infantil, p. 41. 
29. BARBOSA, Sonia de Oliveira. $A$ literatura infantil brasileira e a diversidade cultural, p. 37.

30. COELHO, Nelly Novaes. Literatura infantil: teoria, análise, didática, $\mathrm{p}$. 32 vários autores que refletem sobre diversidade, enfocando as relações entre literatura e seu contexto sociocultural.

Silva (2000), Chauí (2000), Hall (2003), Santos (2006), a Unesco (2009) e Morgado (2010a), todos contribuem para a reflexão sobre a literatura a partir do contexto histórico, sociocultural e cultural em que é produzida, lida e interpretada, a fim de compreendermos as relações de poder existentes e representadas nas obras. ${ }^{29}$

$\mathrm{Na}$ medida em que se torna leitor e sujeito, capaz de uma leitura linguística e semiótica, a criança passa a produzir sua própria leitura do real, reelaborando-o. Ao fazer isso, estará questionando os paradigmas socioculturais e a ideia de normalidade que lhe foi mostrada como normal. A literatura infantil, na medida em que valoriza a litera riedade, discute os padrões linguísticos e culturais, apresenta e defende a diversidade, estará ajudando a criança a ampliar seus horizontes intelectuais e estará realmente educando, no sentido a mplo que apresentamos anteriormente.

As obras literárias se constituem e agem como instrumentos de construção identitária da criança, sendo essas construções no viés individual ou coletivo, que, para Nelly Novaes Coelho, "têm uma tarefa fundamental a cumprir nesta sociedade em transformação: a de servir como agente de formação." ${ }^{30}$ Segundo Barbosa, "foi tomando a literatura infantil como agente de formação da criança que se fundamentou a questão da representatividade da diversidade cultural na literatura infantil". ${ }^{31}$

Para Morgado, a "literatura infantil pode constituir um espaço de representação da diversidade cultural que nos rodeia, de muitas vozes que falam diretamente ao intelecto de leitores sobre muitas coisas, de forma variada." ${ }^{32}$ Nesse sentido, a autora defende a ideia de que toda obra de arte, seja ela de entretenimento ou teórica, surge a partir de um contexto social e político de uma sociedade, respondendo de maneira "estética e ética". Completa que "toda obra de literatura infantil ocupa um espaço político e social, representa e configura relações sociais e culturais de poder e não pode ser separada quer da política quer da história." ${ }^{33}$

Barbosa apresenta a reflexão de Silva sobre a importância da diversidade cultural na escola e da literatura infantil para uma prática social e cultural:

Silva (2011, p. 15), ao abordar a diversidade cultural na escola, corrobora essa inserção da literatura infantil no contexto social e político, e apresenta o desafio de "lidar com a diversidade cultural como princípio educativo, isto é, o entendimento de que o desenvolvimento da prática pedagógica envolve atores sociais e culturais com identificação étnico-raciais, de gênero, de orientação sexual, de deficiências,
31. BARBOSA, Sonia de Oliveira. $A$ literatura infantil brasileira e diversidade cultural, p. 38.

32. MORGADO, Margarida; PIRES, Maria da Natividade. Educacão intercultural e literatura infantil 17-18

33. MORGADO, Margarida; PIRES, Maria da Natividade. Educação intercultural e literatura infantil, p. 18.

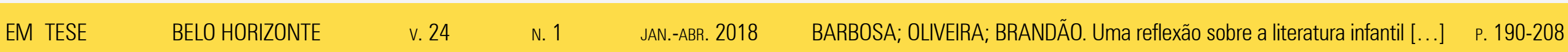


34. BARBOSA, Sonia de Oliveira. $A$ literatura infantil brasileira e diversidade cultural, p. 38

35. SILVA, Natalino Neves. $A$ diversidade cultural como princípio educativo, p. 15 dentre outros, diferentes". Nesse sentido, percebe-se que o autor defende a teoria de que é importante tratar a diversidade como um princípio educativo, explorando a noção de identidade nacional que se efetiva nas experiências sociais e culturais de um indivíduo na sociedade. Sendo assim, a diversidade cultural como princípio educativo leva a refletir sobre valores culturais e sociais do outro, por meio do diálogo racional, até mesmo pelos contos de fadas que representam uma prática social e cultural presentes na formação das crianças, como descreve o próprio Silva (2011, p. 22): "podemos verificar que, ainda hoje, os contos de fada constituem uma prática social e cultural bastante utilizada na formação das crianças da Educação Infantil”. ${ }^{34}$

Se os contos de fada são importantes, é preciso que as crianças tenham acesso a outros textos, de várias origens, em diferentes suportes, de que a literatura infantil é apenas um exemplo, que pode ser bastante diversificado. Textos de autores variados, de épocas diversas e de origens diferentes possibilitam reescrituras do real bastante enriquecedoras. Da mesma forma, suportes diferentes, como livros, revistas, televisão e quadrinhos favorecem a diversidade. De acordo com Silva, "A abordagem da diversidade cultural na escola se realiza, portanto, a partir do encontro de nossos valores simbólicos, sociais, econômicos, culturais e do outro (criança, adolescente, jovem, adulto e idoso), o diferente." ${ }^{35}$ Para que a escola propicie a diversidade cultural, é importante apresentar textos variados, que possibilidade uma leitura crítica. Para Barbosa,

Essa proposta coincide com a desta análise, para quem a diversidade consiste em estabelecer uma oportunidade de relacionar culturas e de estar aberto para diferenças. Portanto, é importante o papel da escola para trabalhar, ou não, a diversidade cultural, principalmente por meio da literatura infantil, nas primeiras séries do ensino fundamental. ${ }^{36}$

A função da literatura, em geral, e da literatura infantil, em particular, seria provocar a leitura crítica, fazendo com que o leitor, especialmente a criança, seja capaz de analisar e questionar os valores cultura is presentes nos textos literários. Ter acesso à leitura e ao código linguístico significa utilizá-los como meios para fazer e refazer a leitura do mundo. Paulo Freire afirma:

A leitura do mundo precede a leitura da palavra, daí que a posterior leitura desta não possa prescindir da continuidade da leitura daquele. Linguagem e realidade se prendem dinamicamente. A compreensão do texto a ser alcançada por sua leitura crítica implica a percepção das relações entre o texto e o contexto. ${ }^{37}$
36. BARBOSA, Sonia de Oliveira. $A$ literatura infantil brasileira e diversidade cultural, p. 39

37. FREIRE, Paulo. A importância do ato de ler em três artigos que se completam, p. 11-12.
EM TESE BELO HORIZONTE $\quad$ v. $24 \quad$ N. $1 \quad$ JAN.-ABr. 2018 BARBOSA; OLIVEIRA; BRANDÃO. Uma reflexão sobre a literatura infantil [...] P. 190-208 
38. CAIEL, A.; OLIVEIRA, R. P. Literatura e diversidade cultural na escola. Dossiê: literatura e ensino, p. 3.
Esse dina mismo da realidade implica em mudança e em diversidade. Nesse sentido, é que Caiel e Oliveira ressaltam que a integração entre leitura do mundo e leitura da palavra, criando novas representações,acaba por integrar escola e literatura: "Levar em conta as diferentes representações cultura is é fundamental para uma educação democrática, e a literatura é um instrumento privilegiado para canalizar a reflexão sobre as formas de significar o mundo e as relações que nele se estabelecem." ${ }^{38}$

A literatura infantil deve enfatizar a diversidade sociocultural ao favorecer os dois tipos de leitura preconizados por Paulo Freire. Não só há diferenças entre os povos, como ta mbém há diferenças dentro do mesmo povo: há etnias e religiões diferentes, há as variadíssimas manifestações culturais, os diversos usos da língua. Perceber as diferenças e refletir sobre elas deve favorecer a aceitação dessas diferenças como algo cria tivo e mutua mente enriquecedor.

A valorização do outro passa por essa percepção da diversidade cultural que a literatura infantil deve mostrar. Como o indivíduo se situa numa sociedade, composta por milhares de outros indivíduos, semelhantes e diferentes entre si, reconhecer a diversidade significa ta mbém reconhecer-se, cada indivíduo funcionando como espelho que reflete e transforma a imagem que capta. Ver a diversidade do outro é ver a própria diversidade. Nesse aspecto, a literatura infantil, ao valorizar a literariedade, a leitura do mundo, a reelaboração do real, estará funcionando como um espelho, no qual o indivíduo se olha e olha o mundo, propiciando a leitura da palavra e a leitura do mundo propostas por Paulo Freire.

\section{CONCLUSÕES}

Yunes e Pondé (1988), Coelho (2000), Zilberman (2003), Morgado (2010a, 2010b), Silva (2011) e Barbosa (2016) destacam a importância da literatura infantil para a formação da criança, por meio da valorização da diversidade. Esses autores estão em consonância com outros autores, como Genette (1982), Chauí (2000), Hall (2003) e Charaudeau (2010). Estes autores apontam para a intertextualidade de todo a to de linguagem, que nunca está sozinho ou isolado, indicam a importância do contexto na compreensão de um texto, e destacam a construção de novos sentidos, não previstos anteriormente pelo autor. Essa interrelação entre textos, entre textos e contexto, e entre o sentido original e novos sentidos, tudo isso permite que se crie um processo dinâmico de produção da diversidade cultural.

Da mesma forma, Freire (1982) acentua esse dinamismo dos atos de linguagem, ao indicar que a leitura da palavra e a leitura do mundo se complementam e, juntas, colaboram para a leitura do contexto. Todos esses autores, cada qual em sua vertente teórica, recusam uma versão única e

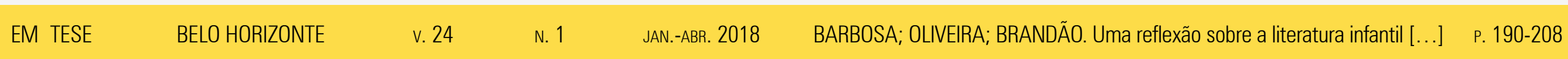


39. UNESCO. Relatório Mundial da UNESCO: investir na diversidade cultural e no diálogo intercultural, p. 3. hegemônica do mundo. Para eles, a riqueza de todo ato de linguagem, especifica mente, aqui, da litera tura infa ntil está em possibilitar a percepção da diversidade.

Pode-se dizer que a cultura, tal como foi conceituada anteriormente neste texto, tem um caráter múltiplo e heterogêneo. Na verdade, seria melhor se se falasse em "culturas", já que a cultura de um povo não é um bloco homogêneo. Segundo a Unesco (2009), nem sempre uma cultura de um estado considera a diversidade cultural como algo positivo e acessível: "Perante essa variedade de códigos e perspectivas, os estados nem sempre encontram as respostas apropriadas, por vezes urgentes, nem logram colocar a diversidade cultural ao serviço do bem comum." ${ }^{39}$. Para essa postura rígida e cerceadora, colaboram os Aparelhos Ideológicos do Estado (ALTHUSSER, 1970) e as formações discursivas (FOUCAULT, 1972), que concorrem para a reprodução das relações de produção, ou seja, para a reprodução e a imposição de um sentido único dos discursos.

Cabe à literatura, e à literatura infantil, como se vem expondo, reagir contra esse estado de coisas. Considerandose que o sentido nunca está completo, essa reação vai depender dos leitores, cuja leitura criativa e libertadora pode ser favorecida pelos próprios textos. No caso específico da literatura brasileira, podem ser citados diferentes autores, mesmo com o risco de omitir nomes significativos, que contribuíram para esse tipo de leitura. Alguns desses autores são Monteiro Lobato, com sua obra pioneira, Cecília Meireles, por sua poesia, Adélia Prado, Maria Clara Machado, Claudius, Daniel Azulay, Ignácio de Loyola Brandão, Ronaldo Simões, Marina Colassanti, Socorro Acioli, Marilda Castanha, André Neves, Nelson Cruz, Bráulio Tavares, Leo Cunha, Ana Maria Machado, Bartolomeu Campos de Queirós, Elias José, Lygia Bojunga Nunes, Ziraldo, Eva Furnari, Chico Buarque, Tatiana Belinky, Ruth Rocha, Ângela Lago, Fernando Vilela, Gabriel, o Pensador, Lino de Albergaria, Nelson Cruz e Jorge Amado.

Uma das limitações deste artigo, dadas as limitações de espaço, é a impossibilidade de se fazer a análise de algumas obras, apontando como elas contribuem para a formação da criança e para diversidade cultural. Entretanto, espera-se ter atingido seu objetivo básico, que é o de refletir sobre a relação da diversidade cultural com a literatura infantil, uma vez que, a nosso ver, essa literatura deve questionar valores e paradigmas da sociedade em que é produzida, a fim de que a criança adquira uma visão crítica sobre sua cultura e sobre si mesma e, ao mesmo tempo em que conhecer o outro e sua diversidade, ta mbém venha a se conhecer. 


\section{REFERÊNCIAS}

ALTHUSSER, Louis. Ideologia e aparelhos ideológicos do estado. Lisboa: Editorial Presença; São Paulo: Livraria Martins Fontes, 1970.

Bakhtin, Mikhail (Volochínov). Marxismo e filosofia da linguagem. Tradução de Michel Lahud, Yara F. Vieira. 2. ed. São Paulo: Hucitec, 198

BARBOSA, Sonia de Oliveira; BRANDÃO, Viviane Bernadeth Gandra. Identidade e alteridade: uma reflexão da obra infantil "O lobisomem que quase morreu de medo". Revista de Estudos de Literatura, Cultura e alteridade - Igarapé, Porto Velho (RO), v. 5 n. 1, p. 242-257, 2017

BARBOSA, Sonia de Oliveira. A literatura infantil brasileira a diversidade cultural. 2016. $122 \mathrm{f}$. Dissertação (Mestrado em Estudos Culturais Contemporâneos) - Universidade Fumec, Belo Horizonte, 2016. p. 37.

BARROS, José Márcio (Org.). Diversidade cultural: da proteção à promoção. Belo Horizonte: Autêntica, 2008.

BETTELHEIM, Bruno. A psicanálise dos contos de fadas. 22. ed. Rio de Janeiro: Paz e Terra, 2007.

CAIEL, A.; OLIVEIRA, R. P. Literatura e diversidade cultural na escola. Dossiê: literatura e ensino. Nau Literária: crítica e teoria de literaturas. PPG-LET-UFRGS, Porto Alegre, v. 6, n. 2, jul./dez. 2010. Disponível em: < http://www. seer.ufrgs.br/NauLiteraria/ article/viewFile/20131/11690 > . Acesso em: 10 jun. 2015.
CANDIDO, Antonio. In: FESTER, A. C. Ribeiro (Org.). Direitos Humanos e Literatura. São Paulo: Brasiliense, 1989.

CARVALHO, Bárbara Vasconcelos de. A literatura infantil: visão histórica e crítica. 3. ed. São Paulo: Global, 1989.

CHARAUDEAU, Patrick. Linguagem e discurso: modos de organização. Tradução de Ângela M. S. Correa e Ida Lúcia Machado. 2 ed São Paulo: Contexto, 2010.

CHAUÍ, Marilena. Convite à filosofia. 13. ed. São Paulo: Ática, 2000

COELHO, L. P.; MESQUITA, D. P. C. Língua, cultura e identidade: conceitos intrínsecos e interdependentes. Entreletras,

Araguaína, v. 4, n. 1, p. 24-34, jan./jul. 2013 (ISSN 2179-3948

online). Disponível em: < http://www.uft.edu.br/pgletras/revista/ capitulos/02_1\%C3\%ADngua,_cultura_e_i dentidade....pdf $>$. Acesso em: 12 mar. 2015.

COELHO, Nelly Novaes. A literatura infantil. 3. ed. ref. ampl. São Paulo: Quíron, 1984

COELHO, Nelly Novaes. Literatura infantil: teoria, análise, didática. São Paulo: 2000.

COELHO, Nelly Novaes. O conto de fadas. São Paulo: Ática 1987. 
CUCHE, Denys. A noção de cultura nas ciências sociais. 2. ed Tradução de Viviane Ribeiro. Bauru: Edusc, 2002, apud GODOY Elenilton Vieira; SANTOS, Vinício de Macedo. Um olhar sobre a cultura. Educação em Revista, Belo Horizonte, v. 30, n. 3, p. 1541, jul./set. 2014.

CUNHA, Maria Antonieta Antunes. Literatura infantil: teoria e prática. 18. ed. São Paulo: Ática, 1999.

ECO, Umberto. Lector in fabula; a cooperação interpretativa nos textos narrativos. Trad. Attílio Cancian. São Paulo:

Perspectiva, 1986

FOUCAULT, Michel.As formações discursivas. In: FOUCAULT Michel. A arqueologia do saber. Tradução de Luiz Felipe Baeta Neves. Petrópolis: Vozes, 1972. p. 31-53.

FREIRE, Paulo. A importância do ato de ler em três artigos que se completam. São Paulo: Autores Associados, Cortez, 1982.

GENETTE, Gérard. Cinq Types de Transtextualité, dont

I'hypertextualité In : GENETTE Gérard. Palimpsestes : I

littérature au second degré. Paris: Éditions du Seuil, 1982. p. $7-63$

GODOY, Elenilton Vieira; SANTOS, Vinício de Macedo. Um olhar sobre a cultura. Educação em Revista, Belo Horizonte, v. 30, n.3, p. 15-41, jul./set. 2014

HALL Stuart. A identidade cultural na pós-modernidade. Rio de Janeiro: DP\&A, 2005.
HALL, Stuart. Da diáspora: identidades e mediações culturais. Belo Horizonte: UFMG, 2003.

HANSEN, João Adolfo. Alegoria: construção e interpretação da metáfora. São Paulo: Atual, 1986

HUNT, Peter Crítica, teoria e literatura infantil São Paulo: Cosac Naify, 2010

LAJOLO, M. Literatura: leitores e leitura. São Paulo: Moderna, 2001.

LAJOLO, M.; ZILBERMAN, R. Literatura Infantil Brasileira histórias \& histórias. São Paulo: Ática, 2007.

LAJOLO, M.; ZILBERMAN, R. Um Brasil para crianças: para conhecer a literatura infantil brasileira: histórias, autores e textos. São Paulo: Global, 1986.

AJOLO, M.; ZILBERMAN, Regina. A formação da leitura no Brasil. São Paulo: Ática, 1985.

MORGADO, Margarida. Literatura Infantil e Interculturalidade: "Preparar os leitores para a vida". Educareducere - Revista da Escola Superior de Educação de Castelo Branco, Rio de Janeiro, Ano 14, jul. 2010a. Edição Fora de Série. Disponível em: <https://cld.pt/dl/download/a6a3156f-2b84-49e0-b4e7a7909197d268/Literatura\%20infantil\%20e\%2OInterculturalidade Preparar\%20os\%20leitores\%20para\%20a\%20vida.pdf >. Acesso em: 3 abr. 2016. 
MORGADO, Margarida; PIRES, Maria da Natividade. Educação intercultural e literatura infantil. Lisboa: Colibri, 2010b.

ROCHER, GUY. Culture, civilisation et idéologie. In: ROCHER,

GUY. Introduction à la Sociologie Générale. $3^{\mathrm{èm}}$. ed. Montréa Éditions Hurtubise HMH Itée, 1992. p. 101-127. Première partie: L'action Sociale, chapitre 4.

SANTOS, José Luís dos. O que é cultura. São Paulo: Brasiliense, 2006.

SILVA, Natalino Neves. A diversidade cultural como princípio educativo. Paidéia, Belo Horizonte, Ano 8, n. 11 p. 13-29, jul./dez. 2011

SILVA, Tomaz Tadeu da. Teoria cultural e educação: um vocabulário crítico. Belo Horizonte: Autêntica, 2000.

SILVA, Tomaz Tadeu. Identidade e diferença: a perspectiva dos estudos culturais. Petrópolis: Vozes, 2013.

SILVEIRA, Rosa Maria Hessel: BONIN, lara Tatiana: RIPOLL,

Daniela. Ensinando sobre a diferença na literatura para crianças: paratextos, discurso científico e discurso multicultural. Revista Brasileira de Educação, [S. I.], v. 15, n. 43, p. 98-108, jan./abr. 2010

UNESCO. Relatório Mundial da UNESCO: investir na diversidade cultural e no diálogo intercultural. [S. I.],

2009. 36 p. Disponível em: <http://unesdoc.unesco.org/

images/0018/001847/184755por.pdf> Acesso em. 13 mar. 2015.
YUNES, Eliana; PONDE, Glória. Leitura e leituras da literatura infantil. São Paulo: FTD, 1988.

ZILBERMAN, R.; CADEMARTORI, Lígia MAGALHÃES.Literatura infantil: autoritarismo e emancipação. São Paulo: Ática, 1982.

ZILBERMAN, Regina. A literatura infantil na escola. São Paulo: Global, 2003.

ZILBERMAN, Regina. Como e por que ler a literatura infantil brasileira. Rio de Janeiro: Objetiva, 2005.
EM TESE
BELO HORIZONTE
v. 24
N. 1
JAN.-ABR. 2018
BARBOSA; OLIVEIRA; BRANDÃO. Uma reflexão sobre a literatura infantil [ . ... P. 190-208

Ensino de Literatura 